\title{
ORIGINAL
} ARTICLES

\section{Promotion of Clinical Educators: A Critical Need in Academic Family Medicine}

\author{
Christine K. Jacobs, MD; Kelly M. Everard, PhD; Peter F. Cronholm, MD, MSCE
}

\begin{abstract}
BACKGROUND AND OBJECTIVES: Academic family medicine departments have traditionally promoted faculty using research and scholarship criteria augmented by teaching, clinical care, and service. Clinic-focused faculty who spend significant time in direct patient care may not have enough time to meet promotion criteria, although they are critical for training future family physicians and for rebalancing the system of academic promotion.
\end{abstract}

METHODS: We surveyed family medicine department chairs on the effects of protected time for scholarship, presence of promotion and tenure $(P$ and $\mathrm{T})$ committees, salary increase, and special promotion tracks on promotion of physician faculty.

RESULTS: Promotion rates to both associate and full professor were higher for faculty with $25 \%$ time for scholarship than for clinic-focused faculty. For clinicfocused faculty, promotion rates to associate professor were higher than they were to full professor. No differences were found for promotion to associate professor and full professor for faculty with $25 \%$ protected time for scholarship. No differences were found in promotion rates for either rank between departments that had P and T committees and those that didn't, whether promotion came with a salary increase, or if departments had a special track for physician faculty whose job is patient care.

CONCLUSIONS: Promotion rates are higher for faculty with protected time for scholarship than for clinic-focused faculty for promotion to both associate and full professor. Clinic demands on faculty may reduce the likelihood of engaging in scholarship or research that in many academic family medicine departments is necessary for promotion.

(Fam Med. 2020;52(9):631-4.)

doi: 10.22454/FamMed.2020.687091

$\Delta$ cademic medicine is at a critical juncture with respect to primary care. In 2017, $42 \%$ of active physicians in the United States were aged 55 years or older. Between 2017 and 2032, the US population is projected to grow by $10 \%$, while the population aged 65 and older is projected to grow by 48\%. The Association of American Medical Colleges (AAMC) projects

2032 , the United States have a shortfall of between 21,100 and 55,200 primary care physicians. To produce medical graduates to address the shortfall, academic medical centers need a large clinician educator (CE) workforce. At the same time, family medicine departments have fiscal constraints that emphasize faculty effort in clinical care over research and scholarship, making it difficult for CEs to get promoted. The competing priorities of medical education, clinical care, and scholarship are front and center in the academic promotion process for CEs.

Academic family medicine departments have traditionally promoted faculty using criteria of research and scholarship augmented by teaching, clinical care, and service to the institution. This began to change in 1990 when Boyer argued that scholarship should include not only the scholarship of discovery (research) but also the scholarship of integration, application, and teaching. ${ }^{1,2}$ In 1999, academic medical leaders described CEs as "mission critical," and called for rebalancing the system of academic promotion which required publications and regional reputation. ${ }^{3}$ In 2005, Fleming et al advocated for a "separate and equitable" promotion track for CEs, with an emphasis on education-specific scholarly productivity. ${ }^{4}$ To further clarify promotion criteria for CEs, in 2006 AAMC endorsed five domains of educational scholarship: teaching, learner assessment, curriculum development, advising and mentoring, and
From the Department of Family and Community Medicine, Saint Louis University School of Medicine, St Louis, MO (Drs Jacobs and Everard); and the Department of Family Medicine and Community Health, Center for Public Health Initiatives, and Leonard Davis Institute of Health Economics, University of Pennsylvania Perelman School of Medicine (Dr Cronholm). 
educational leadership and administration. $^{5}$

Despite the endorsement of educational scholarship, the emphasis on research in academia may leave clinic-focused faculty feeling less valuable than faculty who engage in research. ${ }^{6}$ A 2011 AAMC analysis of faculty retention found a $70 \%$ 5 -year retention rate for clinical family medicine faculty. ${ }^{7}$ In a study of faculty members who left one school of medicine, $66 \%$ of departed faculty cited professional and advancement opportunities as a reason. ${ }^{8}$ At another academic medical center (AMC), global satisfaction was correlated with higher rank. ${ }^{9}$ The replacement cost of generalist clinical academic physicians has been conservatively estimated at over $\$ 115,000 .{ }^{10}$ An effective system of promotion may encourage faculty retention.

A recent Council of Academic Family Medicine Education Research Alliance (CERA) study found that offering protected time for teaching or research was not associated with success in hiring new faculty, ${ }^{11}$ but it is unknown whether protected time for scholarship is associated with promotion rates for CEs in family medicine. In this study we examined the effects of protected time for scholarship, presence of promotion and tenure ( $\mathrm{P}$ and $\mathrm{T}$ ) committees, salary increase, and special promotion tracks on promotion of CEs in academic family medicine.

\section{Methods}

Data were gathered as part of a larger omnibus CERA survey of family medicine department chairs. ${ }^{12}$ Pretesting was done on family medicine educators who were not part of the target population. Questions were modified following pretesting for flow, timing, and readability. Data were collected from August to October 2019 .

The sampling frame for the survey was United States family medicine department chairs as identified by the Association of Departments of Family Medicine. Email invitations to participate were delivered via SurveyMonkey. Four follow-up emails to encourage nonrespondents to participate were sent after the initial email invitation.

The survey was sent to $200 \mathrm{de}-$ partment chairs; one email could not be delivered, and six emails had opted out of SurveyMonkey surveys resulting in a final sample of 193. The American Academy of Family Physicians Institutional Review Board approved the project in August 2019.

\section{Survey Questions}

Respondents answered demographic questions about themselves, their physician faculty, and promotions within their departments. They answered questions about whether their department had a $\mathrm{P}$ and $\mathrm{T}$ committee, whether promotion came with a salary increase, and if they had a special track or promotion criteria for physician faculty whose job is patient care (which may include teaching in the clinical setting) that does not require scholarship, leadership, or service. Chairs also indicated the total number of physician faculty in the department; faculty with at least $25 \%$ protected time for scholarship, research, and/or teaching (regardless of funding source); percent of faculty with at least $80 \%$ clinical time who we refer to as "clinic-focused faculty"; and the number of faculty promoted to associate and full professor in the last 12-months in each of these categories. All questions about faculty referred to physician faculty only.

\section{Analyses}

Data were analyzed using IBM SPSS Statistics for Windows, Version 25.0. (Armonk, NY: IBM Corp). Descriptive statistics summarized data about department chairs, faculty, and promotion criteria. We calculated the percentage of department faculty who had at least $25 \%$ protected time for scholarship and clinic-focused faculty by dividing the number of faculty in each category by the total number of physician faculty. We also calculated the promotion rate of each type of faculty to both associate and full professor by dividing the number promoted in each category by the total number of faculty in the category. Wilcoxon signed rank tests compared promotion rates by type of faculty and faculty rank. Mann Whitney U tests determined associations between having a $\mathrm{P}$ and $\mathrm{T}$ committee and promotion rates to associate and full professor, and associations between a salary increase and promotion rates to associate and full professor.

\section{Results}

Of the 193 department chairs who received the survey, 105 completed it for a response rate of $54.4 \%$. Chairs (61.6\% male; $16.2 \%$ age 40 to 49 years, $36.4 \%$ age 50 to $59,44.4 \%$ age 60 to 69 ) reported that out of 2,093 full-time physician faculty, an average of $47.3 \%(\mathrm{SD}=38.4)$ of their faculty have at least $25 \%$ protected time for scholarship and $28.6 \%$ $(\mathrm{SD}=33.1)$ have $80 \%$ or more clinical time. In $72.2 \%$ of departments, promotions come with a salary increase, $67.4 \%$ of departments have $\mathrm{P}$ and $\mathrm{T}$ committees, and $51.6 \%$ have a special track for physician faculty whose primary role is patient care. Wilcoxon signed rank tests showed promotion rates to both associate and full professor were higher for faculty with $25 \%$ time for scholarship than for clinic-focused faculty (Table 1). For clinic-focused faculty, promotion rates were higher to associate professor than they were to full professor. No differences in rates were found for promotion to associate professor and full professor for faculty with 25\% time for scholarship (Table 2). Mann Whitney $U$ tests showed no differences in promotion rates for either rank between departments that had $\mathrm{P}$ and $\mathrm{T}$ committees and those that didn't, whether or not promotion came with a salary increase, or if departments had a special track for physician faculty whose job is patient care (Table 3 ).

\section{Discussion}

Promotion rates are higher for faculty with protected time for scholarship ( $\geq 25 \%$ protected time for research/scholarship/teaching) than for clinic-focused faculty (faculty 
Table 1: Comparing Promotion Rates of Faculty With $25 \%$ Scholarship Time to Faculty With $\mathbf{8 0} \%$ Clinical Time

\begin{tabular}{|c|c|c|c|}
\hline & $\begin{array}{c}\text { Promotion Rates of Faculty With } 25 \% \\
\text { Scholarship } \\
\text { M (SD) }\end{array}$ & $\begin{array}{l}\text { Promotion Rates of Faculty With } \mathbf{8 0} \% \\
\text { Clinical Time } \\
\text { M (SD) }\end{array}$ & $P$ Value \\
\hline Promotion to associate professor & $15.8 \%(22.0 \%)$ & $9.0 \%(21.2 \%)$ & $.019^{*}$ \\
\hline Promotion to full professor & $10.5 \%(25.7 \%)$ & $1.8 \%(7.9 \%)$ & $.021 *$ \\
\hline
\end{tabular}

*Wilcoxon signed rank test, significant at 0.05 level.

Table 2: Comparing Promotion Rates to Associate Professor and Full Professor

\begin{tabular}{|l|c|c|c|}
\hline & $\begin{array}{c}\text { Promotion to Associate Professor } \\
\text { M (SD) }\end{array}$ & $\begin{array}{c}\text { Promotion to Full Professor } \\
\text { M (SD) }\end{array}$ & P Value \\
\hline Faculty with 25\% scholarship & $15.8 \%(22.0 \%)$ & $10.5 \%(25.7 \%)$ & .071 \\
\hline Faculty with 80\% clinical time & $9.0 \%(21.2 \%)$ & $1.8 \%(7.9 \%)$ & $.002 *$ \\
\hline
\end{tabular}

*Wilcoxon signed rank test, significant at .05 level.

Table 3: Comparing Promotion Rates by Presence of Promotion and Tenure Committee, Salary Increase, and Special Track for Physician Faculty

\begin{tabular}{|c|c|c|c|c|c|c|c|c|c|}
\hline & \multicolumn{2}{|c|}{$\begin{array}{l}\text { Promotion and } \\
\text { Tenure Committee } \\
\text { Mean (SD) }\end{array}$} & \multirow[t]{2}{*}{$\begin{array}{c}P \\
\text { Value }\end{array}$} & \multicolumn{2}{|c|}{$\begin{array}{l}\text { Salary Increase } \\
\text { Mean (SD) }\end{array}$} & \multirow[t]{2}{*}{$P$ Value } & \multicolumn{2}{|c|}{$\begin{array}{c}\text { Special Track } \\
\text { Mean (SD) }\end{array}$} & \multirow[t]{2}{*}{$\begin{array}{c}P \\
\text { Value }\end{array}$} \\
\hline & Yes & No & & Yes & No & & Yes & No & \\
\hline $\begin{array}{l}\text { Promotion rate to associate } \\
\text { professor for faculty with } 25 \% \\
\text { time for research }\end{array}$ & $\begin{array}{c}17.4 \% \\
(21.1 \%)\end{array}$ & $\begin{array}{c}12.3 \% \\
(24.4 \%)\end{array}$ & .098 & $\begin{array}{l}15.9 \% \\
(21.0 \%)\end{array}$ & $\begin{array}{c}17.0 \% \\
(25.7 \%)\end{array}$ & .989 & $\begin{array}{c}17.3 \% \\
(23.7 \%)\end{array}$ & $\begin{array}{c}14.6 \% \\
(20.4 \%)\end{array}$ & .954 \\
\hline $\begin{array}{l}\text { Promotion rate to associate } \\
\text { professor for faculty with } 80 \% \\
\text { clinical time }\end{array}$ & $\begin{array}{c}10.4 \% \\
(22.5 \%)\end{array}$ & $\begin{array}{c}4.9 \% \\
(17.7 \%)\end{array}$ & .060 & $\begin{array}{c}11.6 \% \\
(24.3 \%)\end{array}$ & $\begin{array}{l}2.2 \% \\
(5.0 \%)\end{array}$ & .256 & $\begin{array}{c}13.6 \% \\
(26.9 \%)\end{array}$ & $\begin{array}{c}4.6 \% \\
(13.0 \%)\end{array}$ & .116 \\
\hline $\begin{array}{l}\text { Promotion rate to professor } \\
\text { for faculty with } 25 \% \text { time for } \\
\text { research }\end{array}$ & $\begin{array}{c}10.5 \% \\
(24.9 \%)\end{array}$ & $\begin{array}{c}11.5 \% \\
(30.0 \%)\end{array}$ & .445 & $\begin{array}{c}12.9 \% \\
(28.4 \%)\end{array}$ & $\begin{array}{c}4.0 \% \\
(13.8 \%)\end{array}$ & .264 & $\begin{array}{c}11.4 \% \\
(27.9 \%)\end{array}$ & $\begin{array}{c}10.0 \% \\
(24.0 \%)\end{array}$ & .222 \\
\hline $\begin{array}{l}\text { Promotion rate to professor } \\
\text { for faculty with } 80 \% \text { clinical } \\
\text { time }\end{array}$ & $\begin{array}{c}0.5 \% \\
(1.9 \%)\end{array}$ & $\begin{array}{c}6.4 \% \\
(16.0 \%)\end{array}$ & .432 & $\begin{array}{l}1.0 \% \\
(5.1 \%)\end{array}$ & $\begin{array}{c}5.2 \% \\
(14.4 \%)\end{array}$ & .071 & $\begin{array}{c}0.3 \% \\
(1.4 \%)\end{array}$ & $\begin{array}{c}3.3 \% \\
(11.0 \%)\end{array}$ & .385 \\
\hline
\end{tabular}

Mann-Whitney $U$ tests, none significant at .05 level.

with $\geq 80 \%$ clinical time). We found this for promotion both to associate and full professor. There are several possible reasons for the lack of advancement of clinic-focused faculty. Clinical and academic demands on faculty can reduce the likelihood of engaging in research, ${ }^{13}$ which in many AMCs is necessary for promotion. One study found that physician faculty with more than $50 \%$ of time in clinical care had slower career progress, were less likely to be at rank of professor, and had lower commitment to academic careers than peers with less than $50 \%$ clinical time. ${ }^{14}$
Clinic-focused faculty are promoted at much lower rates to full professor than they are to associate professor, whereas faculty with protected time for scholarship are promoted at similar rates to associate and full professor. Advancement to professor generally requires a higher level of scholarship than advancement to associate professor, and clinic-focused faculty may not have enough time to engage in activities that would help them meet that higher bar. The emphasis on research over teaching in medical education has led to lower professional satisfaction, promotion, retention, and pay for clinical faculty. ${ }^{15}$ Faculty who spend the great majority of time in patient care may not see value in attaining the rank of professor. There may also be insufficient incentives for predominantly clinical faculty to stay in academic departments for the number of years required to attain rank of professor.

It appears that financial incentives may not increase promotion rates. Although the majority of departments couple promotion with a salary increase, this was not associated with a higher promotion rate. Departments with $\mathrm{P}$ and T committees did not have more promotions than those without. $\mathrm{P}$ and $\mathrm{T}$ committees with an evaluative role 
may simply be a step in the promotion process, rather than providing the mentoring and tracking necessary for promotion. In one study, internal medicine department chairs and $\mathrm{P}$ and $\mathrm{T}$ committees both valued teaching skills and clinical skills for promotion of clinical faculty, but department chairs valued educational activities, research related to education, and clinical productivity more highly than $\mathrm{P}$ and $\mathrm{T}$ committees did. ${ }^{16}$ Such lack of agreement about performance measures can be a barrier to promotion. A 2011 literature review concluded that "succinct, discrete definitions of clinical scholarship have been published in other disciplines, but not in academic medicine." ${ }^{17}$ There may be a way to maximize promotions by involving departmental $\mathrm{P}$ and $\mathrm{T}$ committees in defining and clarifying evaluation of educational scholarship and providing sufficient milestone evaluation and mentorship for faculty promotions.

Half of departments in this survey had a special clinical track for physician faculty whose job is primarily patient care (which may include teaching in the clinical setting) that does not require scholarship, leadership, or service, but that was not associated with promotion rates. There is great variation in faculty tracks nationwide. One analysis distinguished clinician educator $(<50 \%$ patient care), clinical (90\%-100\% patient care) and educator ( $>50 \%$ education). Of the first two tracks, $25 \%$ were tenured in 2009. ${ }^{18}$ The lack of a higher promotion rate to professor in departments with a clinical track may be a result of clinical tracks being a relatively recent phenomenon in some AMCs, or a lack of expectation for clinical faculty to achieve the rank of professor.

This study was limited by the scope of the survey questions. We queried department chairs about physician promotions in the last year, rather than a longer period of time, to reduce inaccurate recall of more distant events, although we realize that promotions from only 1 year may not be sufficiently representative. We may have had a more accurate picture of promotion rates if we had asked about the previous 2 or 3 years. We categorized faculty into at least $25 \%$ protected time and at least $80 \%$ clinical time. Faculty time is much more nuanced, but in our experience those distinctions are clear in effort calculations. We did not ask about tenure or the implications of not achieving promotion (ie, institutions with up-or-out tracks), but it is possible that availability of tenure might influence promotion trajectories.

We did not ask about the role of the department $\mathrm{P}$ and $\mathrm{T}$ committee. In most departments, $\mathrm{P}$ and T committees serve an evaluative function, but $\mathrm{P}$ and $\mathrm{T}$ committees could positively influence promotion by providing mentoring, or by refinement of educator evaluation systems within each institution.

Future study should query the reason for the drop-off in promotions to professor for clinic-focused faculty.

\section{Conclusions}

In academic family medicine, clinic-focused faculty are promoted at lower rates than faculty with protected time for scholarship. Salary increases, department $\mathrm{P}$ and T committees, and separate clinical tracks were not associated with promotion rates. We must learn more about the incentives for clinic-focused faculty to remain in academic medicine because they are key educators and mentors for the next generation of primary care physicians. ${ }^{4}$

CORRESPONDING AUTHOR: Address correspondence to Dr Christine K. Jacobs, Department of Family and Community Medicine, Saint Louis University School of Medicine, 1402 S Grand Blvd, St Louis, MO 63104. 314-977-8480. 314-977-5268. Christine.jacobs@ health.slu.edu.

\section{References}

1. Boyer E. Scholarship Reconsidered: Priorities of the Professoriate. Lawrenceville, NJ: Princeton University Press; 1990.

2. Glassick CE. Boyer's expanded definitions of scholarship, the standards for assessing scholarship, and the elusiveness of the scholarship of teaching. Acad Med. 2000;75(9):877-880.
3. Levinson W, Rubenstein A. Mission critical-integrating clinician-educators into academic medical centers. N Engl J Med. 1999;341(11):840-843.

4. Fleming VM, Schindler N, Martin GJ, DaRosa DA. Separate and equitable promotion tracks for clinician-educators. JAMA. 2005;294(9):1101-1104.

5. Simpson D, Fincher RM, Hafler JP, et al. Advancing educators and education by defining the components and evidence associated with educational scholarship. Med Educ. 2007;41(10):1002-1009.

6. Kumar K, Roberts C, Thistlethwaite J. Entering and navigating academic medicine: academic clinician-educators' experiences. Med Educ. 2011;45(5):497-503. $\underline{\mathrm{d}}$

7. Corrice A, Fox S, Bunton S. Retention of FullTime Clinical M.D. Faculty at U.S. Medical Schools. Vol 11. Washington, DC: Association of American Medical Colleges; 2011:1-2.

8. Girod SC, Fassiotto M, Menorca R, Etzkowitz H, Wren SM. Reasons for faculty departures from an academic medical center: a survey and comparison across faculty lines. BMC Med Educ. 2017;17(1):8.

9. Thomas PA, Diener-West M, Canto MI, Martin DR, Post WS, Streiff MB. Results of an academic promotion and career path survey of faculty at the Johns Hopkins University School of Medicine. Acad Med. 2004;79(3):258-264.

10. Schloss EP, Flanagan DM, Culler CL, Wright $\mathrm{AL}$. Some hidden costs of faculty turnover in clinical departments in one academic medical center. Acad Med. 2009;84(1):32-36.

11. Everard KM, Zoberi K, Jacobs C. Factors Associated With Successfully Filling Faculty Vacancies in Family Medicine. Fam Med. 2019;51(6):489-492.

12. Seehusen DA, Mainous AG III, Chessman AW. Creating a centralized infrastructure to facilitate medical education research. Ann Fam Med. 2018;16(3):257-260.

13. Brocato JJ, Mavis B. The research productivity of faculty in family medicine departments at U.S. medical schools: a national study. Acad Med. 2005;80(3):244-252.

14. Buckley LM, Sanders K, Shih M, Hampton CL. Attitudes of clinical faculty about career progress, career success and recognition, and commitment to academic medicine. Results of a survey. Arch Intern Med. 2000;160(17):26252629 .

15. Irby DM, O'Sullivan PS. Developing and rewarding teachers as educators and scholars: remarkable progress and daunting challenges. Med Educ. 2018;52(1):58-67.

16. Atasoylu AA, Wright SM, Beasley BW, et al. Promotion criteria for clinician-educators. J Gen Intern Med. 2003;18(9):711-716

17. Grigsby RK, Thorndyke L. Perspective: recognizing and rewarding clinical scholarship. Acad Med. 2011;86(1):127-131.

18. Coleman MM, Richard GV. Faculty career tracks at U.S. medical schools. Acad Med. 2011;86(8):932-937. 